\title{
Exhibitions and the Formation of Knowledge
}

JAŚ ELSNER, CORPUS CHRISTI COLLEGE, OXFORD; DIVINITY SCHOOL, UNIVERSITY OF CHICAGO

$\mathrm{I}$

N WHAT SENSE IS AN exhibition the basis for knowledge? I ask myself the question because I have, for the first time, curated a large show comprising major loans-the result of a long academic project entitled Empires of Faith (based at the British Museum and in Wolfson College, Oxford). The exhibition, called Imagining the Divine: Art and the Rise of World Religions, explores the ways the visual identities of the world religions were formed during the first millennium through interaction, dialogue, encounter, and self-conscious differentiation through divergence. ${ }^{\mathrm{I}}$ The curatorial team has focused on the formative periods in the arts of Hinduism, Buddhism, Islam, Judaism, and Christianity across Eurasia from India to Ireland. The result has been on show at the Ashmolean Museum in Oxford between October 2017 and February 2018.

Now when I started in 2015, alongside a wonderful and dynamic team of cocurators who had been researchers working with me since 2013, my sense was that an exhibition is the result of knowledge. It is a kind of distillation, the telling of a particular story_inevitably highly

(c) 2018 BY THE UNIVERSITY OF CHICAGO. ALL RIGHTS RESERVED. KNOW V2N2, FALL 2018 
targeted and abbreviated since one can only display about I50 objects. This is not only a constraint of space, given the particular galleries available at the Ashmolean, but also (as importantly) one of the attention span of even a significantly interested and committed visitor. We all know about those exhibitions that are simply too big to take in.

Of course, the view that any exhibition is the expression of something already known is obvious, and obviously right. But it is also a crude way of seeing the dynamic life of a process that is closer to putting on a play with multiple people involved (often in the backgroundsets, costumes, lighting, choreography) than it is to the writing of a book, which is typically under the control of a single author whose name appears on the cover. No one person (or group) can control an exhibition - the design, the lighting, the internal arrangement of each case, the structure of the narrative, relations with lenders and conservators that determine certain decisions of display, the specific wording of every caption and panel, the orchestration of how visitors may choose to walk the show, and so on. In this sense an exhibition is a living dynamic-a long process of planning and preparation, a great explosion of energy in the final setting up, a living experience for both curators and visitors, an existential choice (even a financial choice) for those who decide to see it about what to do at that particular time, when one might go to a movie, go to the theater, go for a walk, or have a nap. Moreover, at least for many visitors, an exhibition is a shared, even a collective experience-not a thing you do alone. In all this the show itself is so fundamentally different from its catalog, the book that proclaims to be a record but of course had to be written and sent to press well before you knew what the final objects were going to be! The catalog is a record, at best, of a process in progress and not complete, of an idea before it has come to be instantiated in threedimensional form. But the show itself, in one sense the result of knowledge, becomes a new kind of basis for knowledge, produced by a mul- 
as certain issues only become clear at the last moment, when the objects that one borrows are unpacked and put into cases.

The most fundamental problem for the knowledge question is that objects do not speak. They exist in the world and they manifest through medium, decoration, the particularities of their form of being. That manifestation has been specially emphasized, spotlit one might say, through the choice to exhibit these particular things in this particular set of display cases and rooms. In our case that was a large story about five world religions concentrated in three not enormous but flexibly adaptable galleries. One may delude oneself that the captions one writes-all of forty words long-somehow speak for the objects or let them tell their tale (that is, if a visitor bothers to read them). But objects also make claims through their contiguity and placement, and some of these arguments manifest across immediate juxtapositions in relation to other objects seen earlier and later. Sometimes one can plan these kinds of apparently happenstance dialogues-for example, in Imagining the Divine, a ninthcentury vellum illumination of an intricate carpet page from a fine Qu'ran from Egypt in the last gallery (fig. I), may resonate with an opening of two carpet pages from a tenth-century paper codex of Exodus made for Karaite Jews, probably in Egypt, whose text was written in Arabic, displayed in the first gallery (fig. 2). Likewise, a luxury Qu'ran written on blue-dyed parchment in imitation of the deluxe purple parchment books of Byzantium displayed among the calligraphic masterpieces of early Islam (fig. 3) speaks to an Anglo-Saxon royal manuscript page, dyed purple in emulation of Byzantine models and inscribed with letters of silver and gold (fig. 4). In both these instances, we showed the objects in separate rooms (the Jewish and the Islamic sections; the Islamic section and that on the Christian arts of the British Isles), but to an attentive visitor we hoped they might "speak." That connection was not the story that we told, but it is a story we hoped that the exhibition allows itself to tell. 


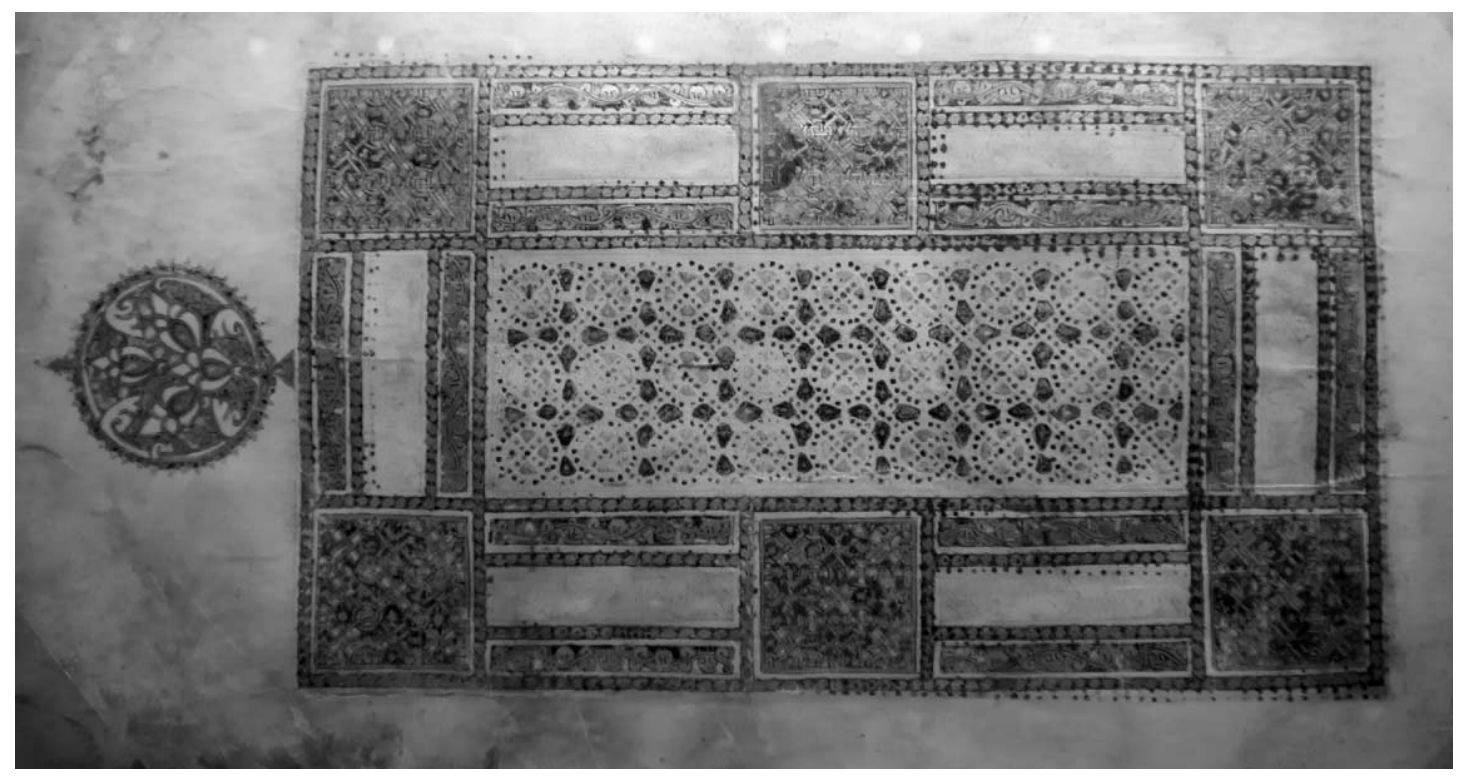

Figure 1.

Illuminated carpet page from a Qu'ran, ink and gold on parchment, ca. 800-900 CE, perhaps from Egypt. From the Sarikhane Collection I. Ms. 1026. Display photograph: Stefanie Lenk. Color version available as an online enhancement.
An entirely different kind of narrative, created by the selected objects themselves, lay in the controversial choice to use copies of a few special pieces that we were unable to borrow. (One man, in response to a talk I gave to introduce the show in the run-up period before it opened, called this decision the "thin end of the wedge" and implied the Ashmolean was taking exhibition culture to new lows.) These copies themselves made up an extraordinary historical taxonomy of the range of ways in which objects have been replicated from the seventeenth century to the twenty-first. That was never the subject of our show, nor has it any place in our catalog, but it is part of the exhibition's story and it is one of the forms of knowledge that it offers. To display the interface of imperial power and apotheosis in the ancient world, we asked to borrow the Grand Camée de France, the largest Roman cameo gem that survives (made for the imperial court at Rome in the first century CE), from the Cabinet des Médailles in Paris. Not surprisingly, given that it is a national treasure, the mu- 


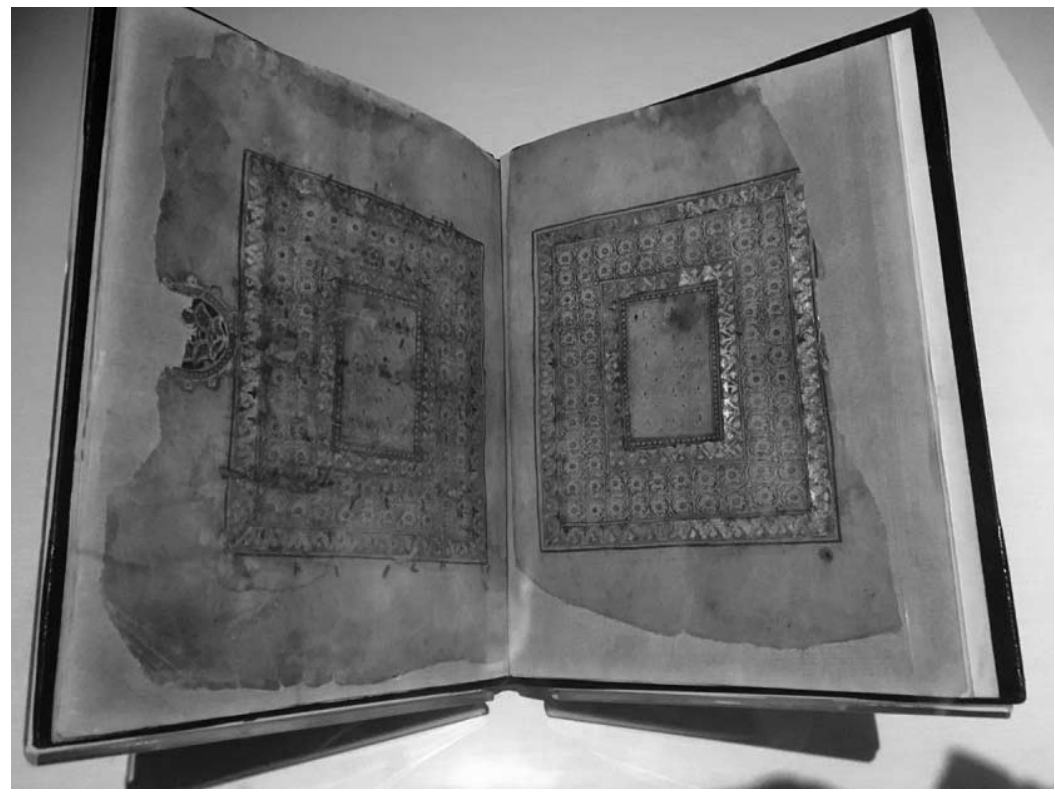

Figure 2.

Illuminated pair of facing carpet pages from a Jewish Karaite Book of Exodus (written in Arabic), ink and gold on paper, after $900 \mathrm{CE}$, from Egypt. From the British Library Or. Ms. 2540. Display photograph: Katherine Cross. Color version available as an online enhancement.

seum said no. But in 1626 Rubens produced a magnificent painted copy, much larger and arguably clearer than the original, which once belonged to the great French antiquarian Fabri de Peiresc and has hung in the Ashmolean since I990 (fig. 5). This we were able to have. It documents a wonderful model of early modern reproduction where the replica is arguably as magnificent as the original. The most famous reliquary casket of Buddhist India is a gilt bronze box with an image of the Kushan emperor, Kanishka (alongside the Buddha, and the Indian gods Indra and Brahma), from the second century $\mathrm{CE}$, which was found in Peshawar (fig. 6, right-hand side). Once the property of the Raj, this object stayed in Pakistan, but a plaster cast, perhaps modeled after an electrotype copy in the British Museum or perhaps taken from the original, found its way into the Ashmolean. Here we have an example of the prime model of replication of threedimensional objects throughout the nineteenth and early twentieth 


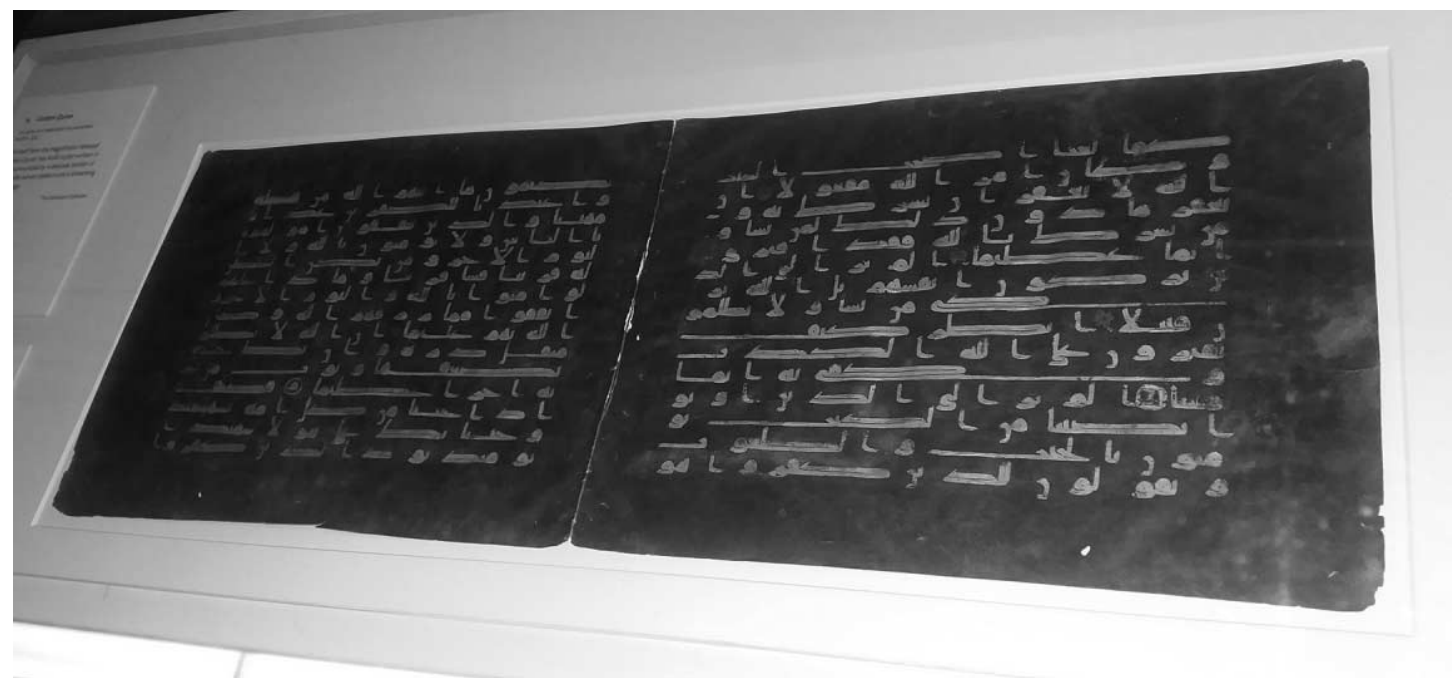

Figure 3.

Two leaves from the Blue Qu'ran, gold and silver ink on blue-dyed parchment, ca. 800-900 CE, from Baghdad. From the Sarikhane Collection I. Ms. 1024. Display photograph: Jaś Elsner. Color version available as an online enhancement. centuries, and at the same time a document of colonial rule and the division of the Indian heritage at the end of Empire. Perhaps the most distinguished British object of about $700 \mathrm{CE}$ in the British Museum is the Franks Casket, made of whalebone, inscribed in runes and in Latin, carved with intricate scenes of Germanic myth, Christian scripture, Romulus and Remus, and the sack of Jerusalem. Of course they do not lend it. But instead they sent us a superb resin replica made in 1996-so good that you need to look with care (and not through a glass case) to be sure of the difference (fig. 7). Yet this state-of-the-art object, so very recent, is itself the relic of a predigital age. Our final replica we made ourselves-having secured generous private funding. The greatest surviving rock crystal masterpiece of pre-Islamic Persian art is the Khosro Cup, probably made in the sixth century, now in the Cabinet des Médailles. The museum generously allowed us to scan the original with the most up-to-date equipment (we sent a team to Paris) and produce a $3 \mathrm{D}$ print in polymer resin, finished with acrylic paint, lacquer, and gold leaf (fig. 8). It 


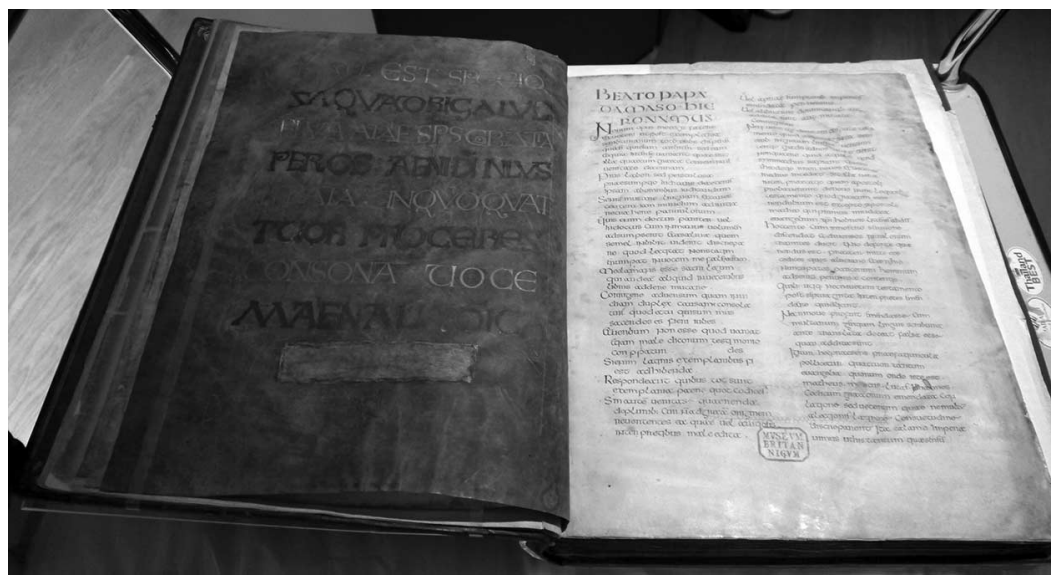

Figure 4 .

Opening including a purple page from an Anglo-Saxon royal Bible, tempera, gold and silver ink on parchment, ca. 800-850 CE, from Canterbury. From the British Library, Royal MS E vi. Installation photograph while on the trolley about to be put into the case: Jaś Elsner. Color version available as an online enhancement.

was never our intention to recount the history of state-of-the-art replication in the world of precious objects from the early modern period to the contemporary moment. But one can tell that story through our show.

One final replica in the show was a large-scale photograph (3.5 meters high) of the earliest colossal Buddha to survive into the twenty-first century, the largest of the two monumental rock-cut standing statues from Bamiyan in Afghanistan, made toward the end of the sixth century and described by the Chinese traveler Xuanzang in the early seventh (fig. 9). Within the line and range of copies in the exhibition, this is perhaps the most common of modern options, in this case an analogue color photograph from the I970s turned into a digital image and printed as a large-scale poster. Within the exhibition it raised the further problematic of iconoclasm in religious art and among religions as part of the polemical discourse of religious visual culture. But iconoclasm is not simple. The Bamiyan statues had been defaced long ago, certainly by Muslim rulers of the area, but preserved their form and structure. Their finer details, modeled in mud mixed with straw and coated with painted stucco, had 
Figure 5.

Peter Paul Rubens (1577-1640),

glorification of a Roman emperor, after the Grand Camée de France, oil on canvas, $100.7 \mathrm{~cm} \times$

$78 \mathrm{~cm}$. Ashmolean Museum

WA1989.74. Display photograph:

Jaś Elsner. Color version available

as an online enhancement.

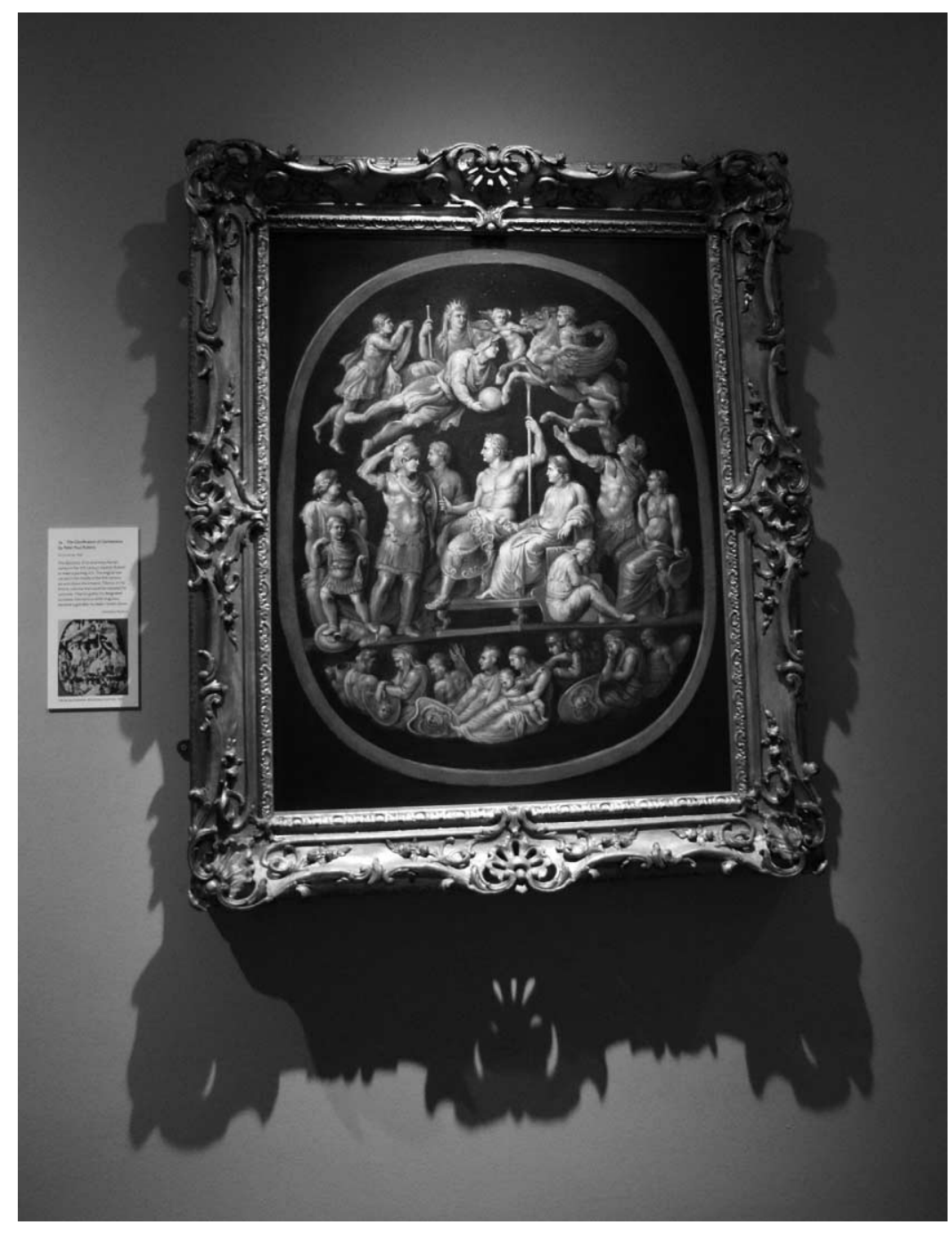




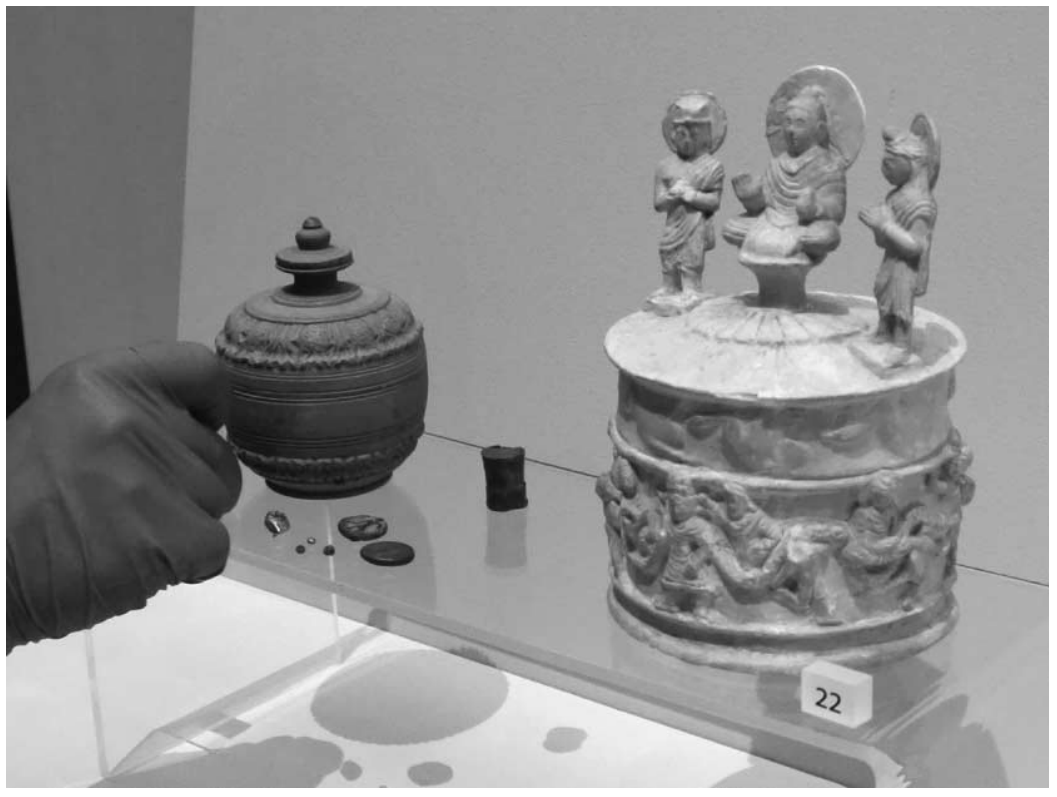

long vanished-partly the natural result of deterioration in time. Notoriously, in March 200I, the Taliban government of Afghanistan demolished all that remained of the two standing statues using dynamite, but not the niches in which they stood. They justified this act by an interpretation of Islamic law as enjoining the destruction of idols. Within the show the Bamiyan figures at the end of the Buddhist section (depicted in predemolished form and not emphasizing the Taliban end of their story) were immediate precursors of two objects in the following section on the rise of Islamic art. One was a small South Arabian calcite stele, made before $300 \mathrm{CE}$ with possibly votive and possibly funerary functions, which boasts the inscription "image of Rabi'at," but with the standing figure of Rabi'at clearly obliterated, whether by later Muslim inhabitants of the peninsula or earlier. The second was a slab of carved basalt from Bengal, at the borders of India and Bangladesh, with a fine fifteenth-century
Figure 6.

Two Buddhist reliquaries. Left side, carved schist from Gandhara with its contents, ca. 300-500 CE; right side: twentieth-century plaster cast of the Kanishka Casket from Peshawar (ca. 150-200 CE). Installation photograph: Jaś Elsner. Color version available as an online enhancement. 
Figure 7.

Twentieth-century resin replica of the Franks Casket, originally made in whalebone ca. $700 \mathrm{CE}$ in northern England, showing the front side with the Magi to the right and a scene of Germanic legend to the left. Display photograph: Jaś Elsner. Color version available as an online enhancement.

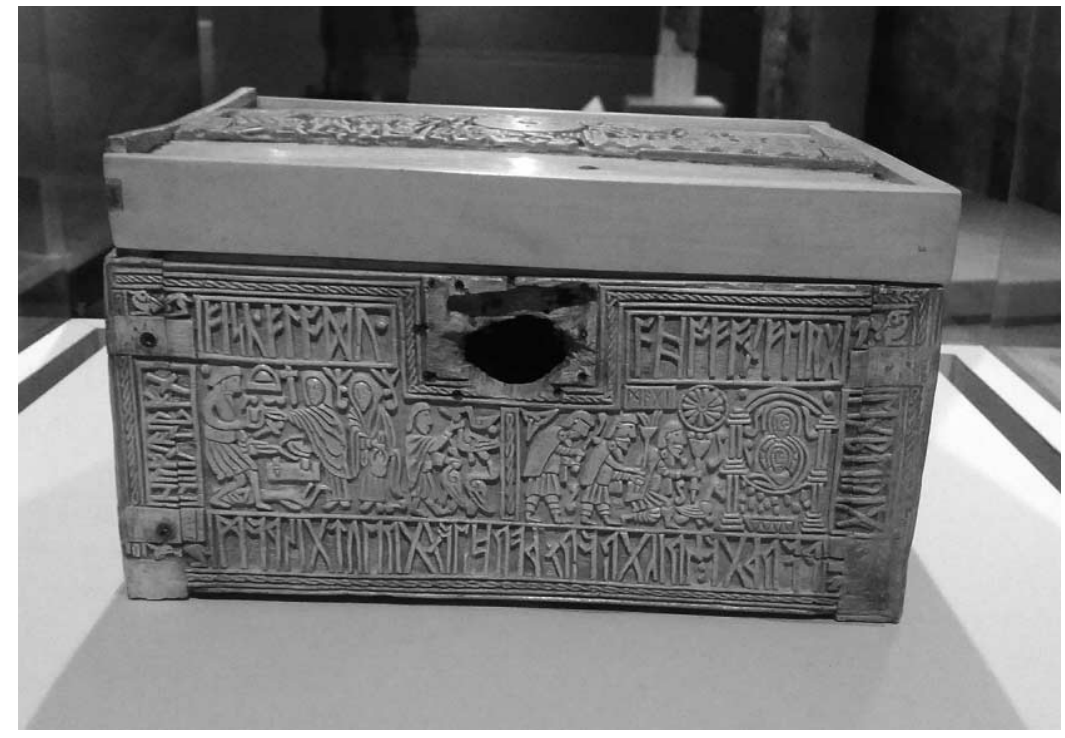

ornamental design on what was once the back, which was used as part of the extensive decoration of the interior of a mosque. The former front, carved in the tenth century and embedded into the plaster of the mosque's interior to hide it when the object was repurposed and its back carved, shows a Tantric goddess (fig. Io)-probably one of the accompanying deities of a Buddha, such as one finds on Tibetan thangkas, such as the fifteenth-century example at the introduction to the show (fig. I I). The figure has been very carefully preserved, with only some damage to her breasts and the nose of her front face (but not the remaining three), but all her defining attributes have been deliberately chiseled away so as to deprive her both of power and identity. Here we have a model of respect combined with partial destruction, and a rather expert knowledge of what to demolish (in another religion's sacred art) both to limit the object's agency and not to provoke an excessive retributive response from it. These pieces-alongside the borrowings of iconographies (e.g., of the seated Buddha form 


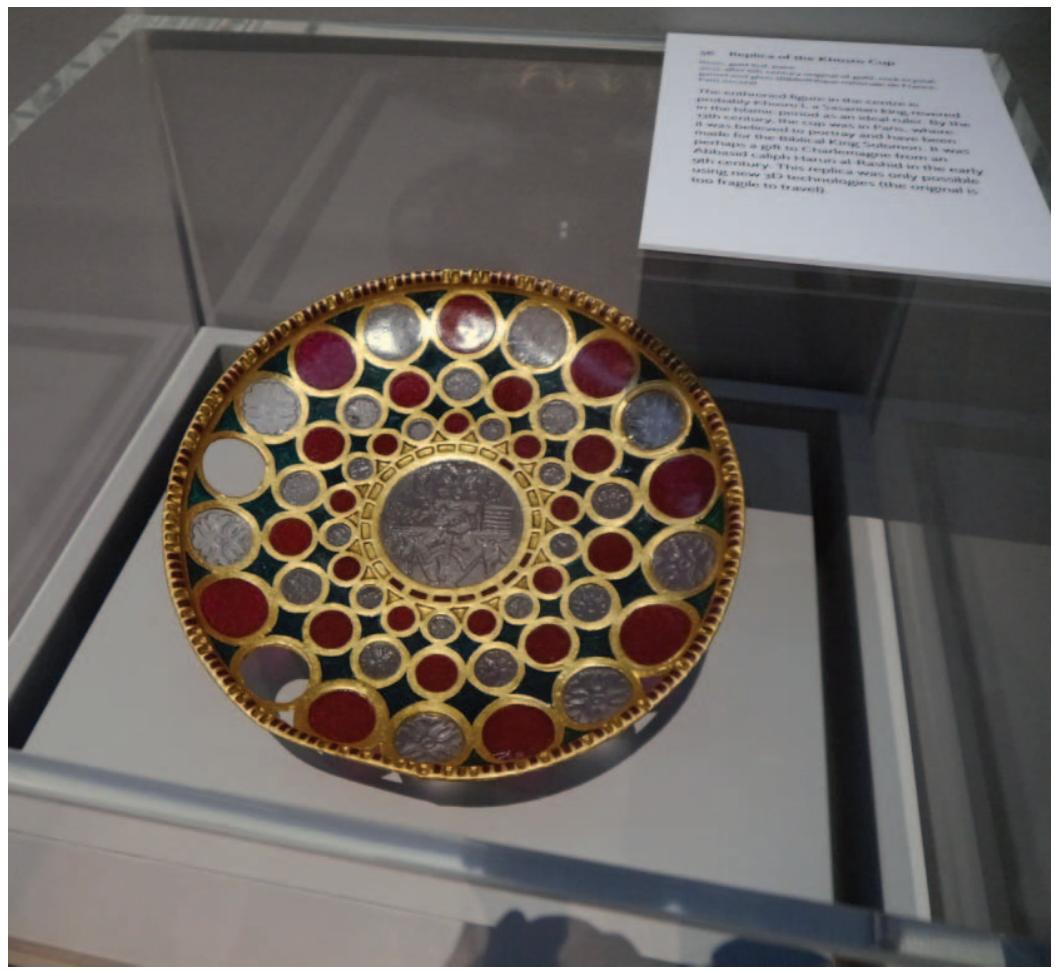

Figure 8.

Twenty-first-century $3 \mathrm{D}$ print in polymer resin with acrylic paint, gold leaf, and lacquer finish, of the Khosro Cup, made in rock crystal between 500 and $650 \mathrm{CE}$ in Persia and showing the Sasanian king in the center. Installation photograph with label still to be placed: Jaś Elsner.

with topknot in an Abbasid lusterware bowl from Mesopotamia, fig. I2) evoke the complex nature of polemical and apologetic visual discourse that was the normal interchange of relations between religions throughout antiquity and the medieval world. We did not make the iconoclasm issue or that of polemic and apologetic into major themes of the show's story, but did highlight them in the catalog. ${ }^{2}$

Our ostensible subject in the show was to explore the ways objects make religion, and the ways their material dialogue has constructed so much of religious identity. This is constitutively not an argument of the kind made by scriptural texts or their commentaries-the normal fare in the study of religions, and one that all too often excludes 
Figure 9.

Photograph of the larger of the Bamiyan Buddhas. Installation photograph: Jaś Elsner. Color version available as an online enhancement.

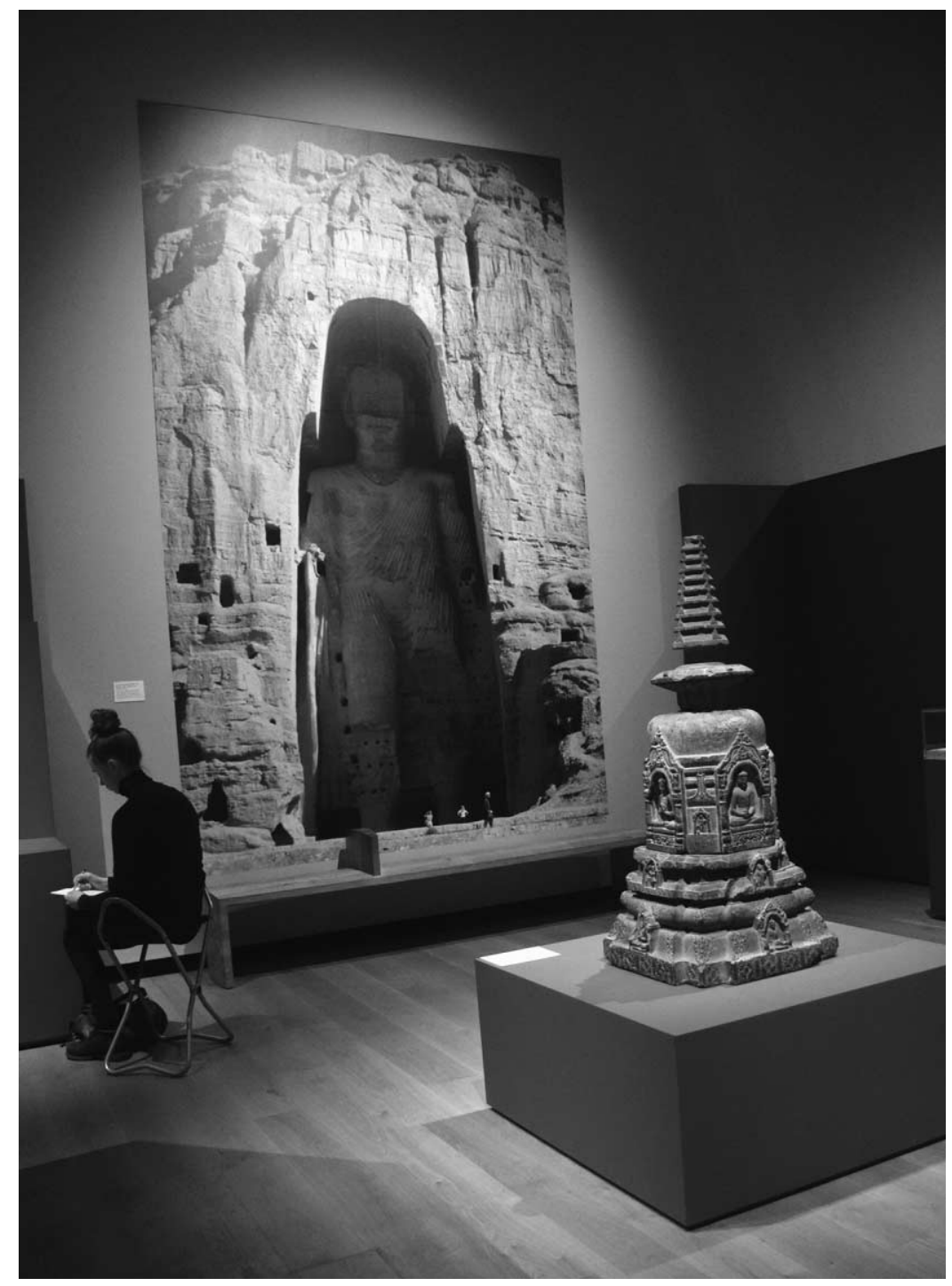




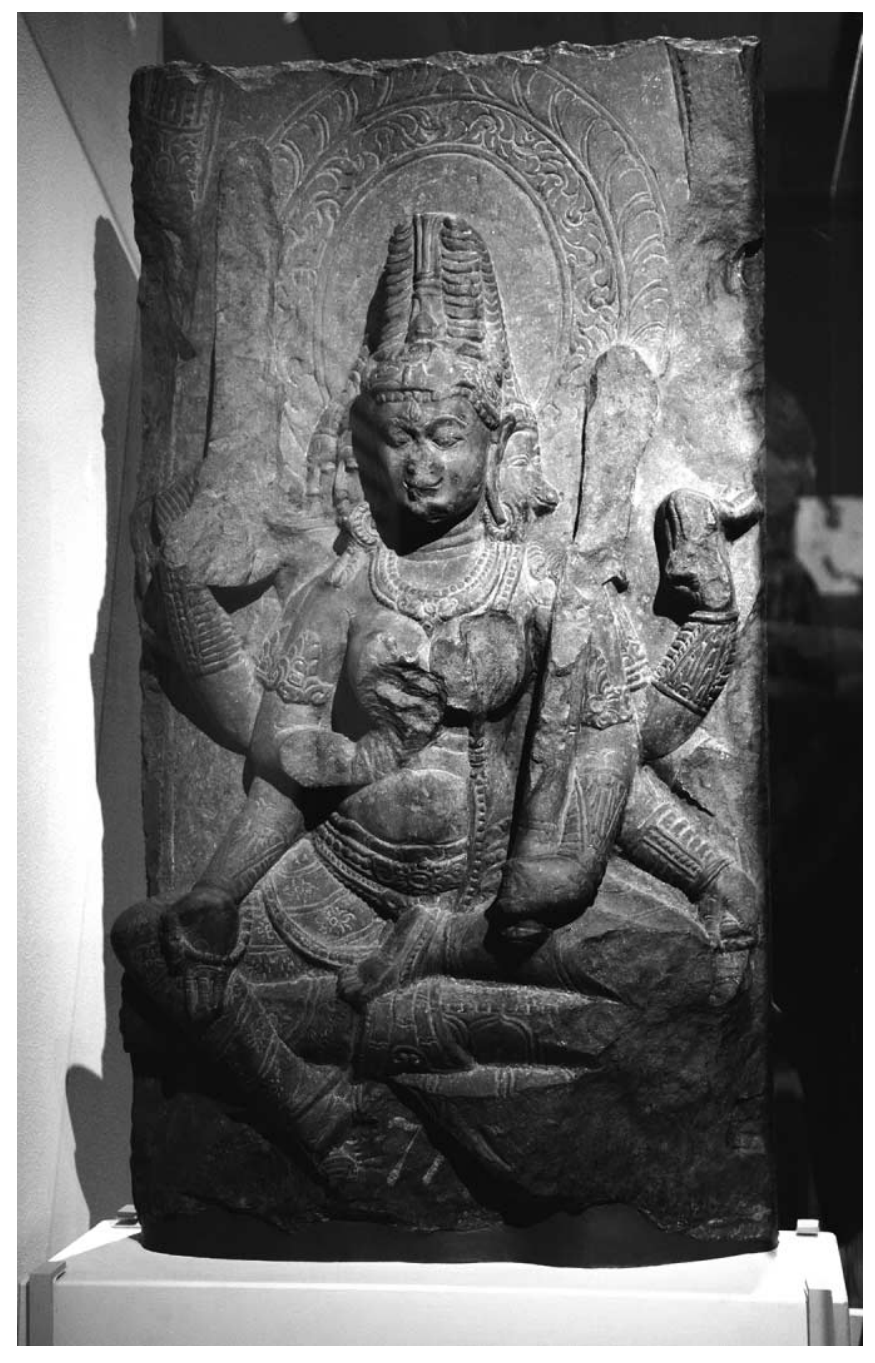

Figure 10.

Partially demolished relief of a

Tantric goddess, ca. 900-

$1000 \mathrm{AD}$, made in northern India,

found reused in a mosque at

Gaur in Bengal. British Museum

1872.0701.42.A. Display photo-

graph: Jaś Elsner. Color version

available as an online enhance-

ment. 
Figure 11.

Female Tantric deity, detail from a Thangka showing the Buddha made in Tibet, ca. 1460-1500. Tempera on silk. Bodleian Library, on loan to the Ashmolean Museum, inv. 79/3. Installation photograph: Jaś Elsner.

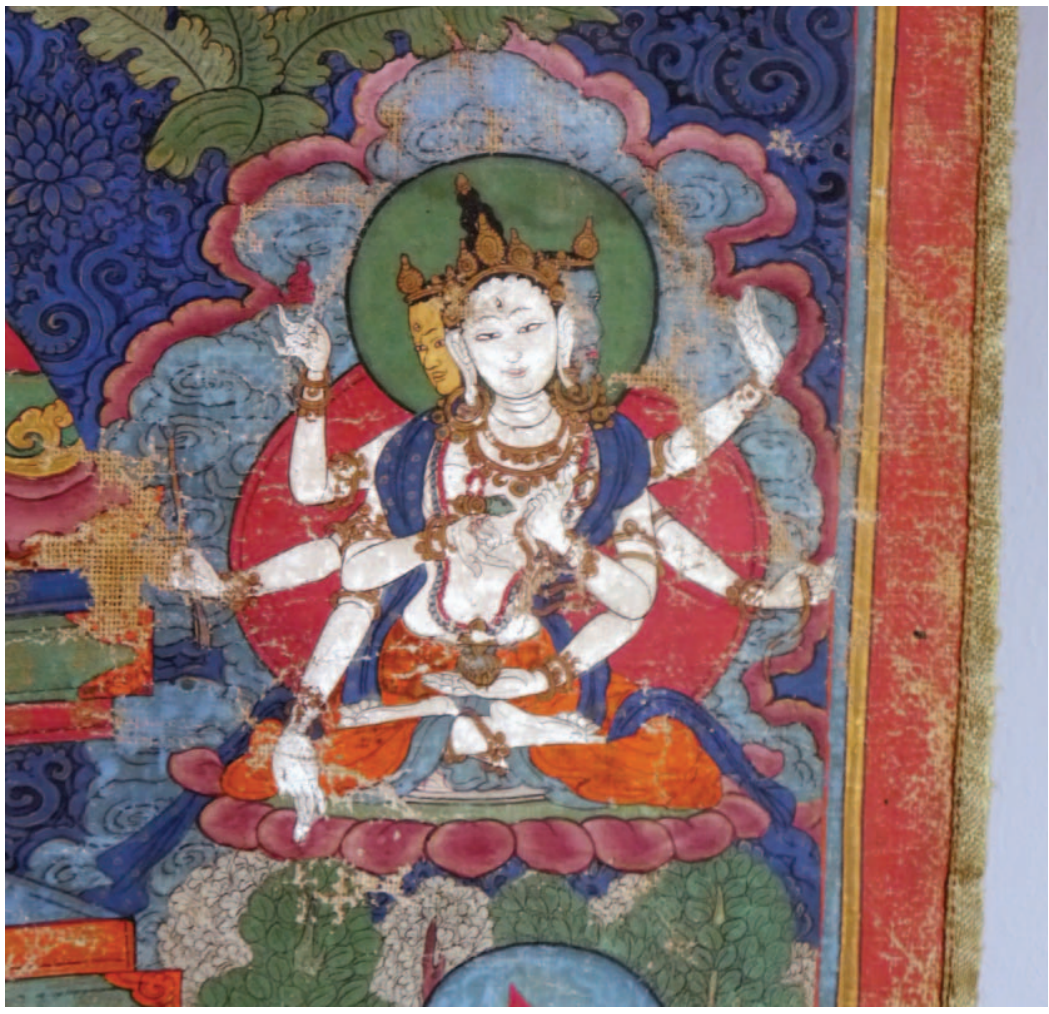

visual and material culture. We have amassed what we believe to be typical but high-quality objects, which in themselves make a series of existential statements that cannot be easily defined as the kinds of propositions or formal arguments one can make through textual discourse. Yet each object is a religious claim, and may carry a theological charge, both in its time of making and in its later receptions, and again in their contiguities objects offer further implications.

Among the Buddhist pieces, spanning the Silk Road, is a fine stupa, or reliquary mound (say three feet high) of about $800 \mathrm{CE}$ from Bodhgaya, the site of the Buddha's Awakening in northern India 


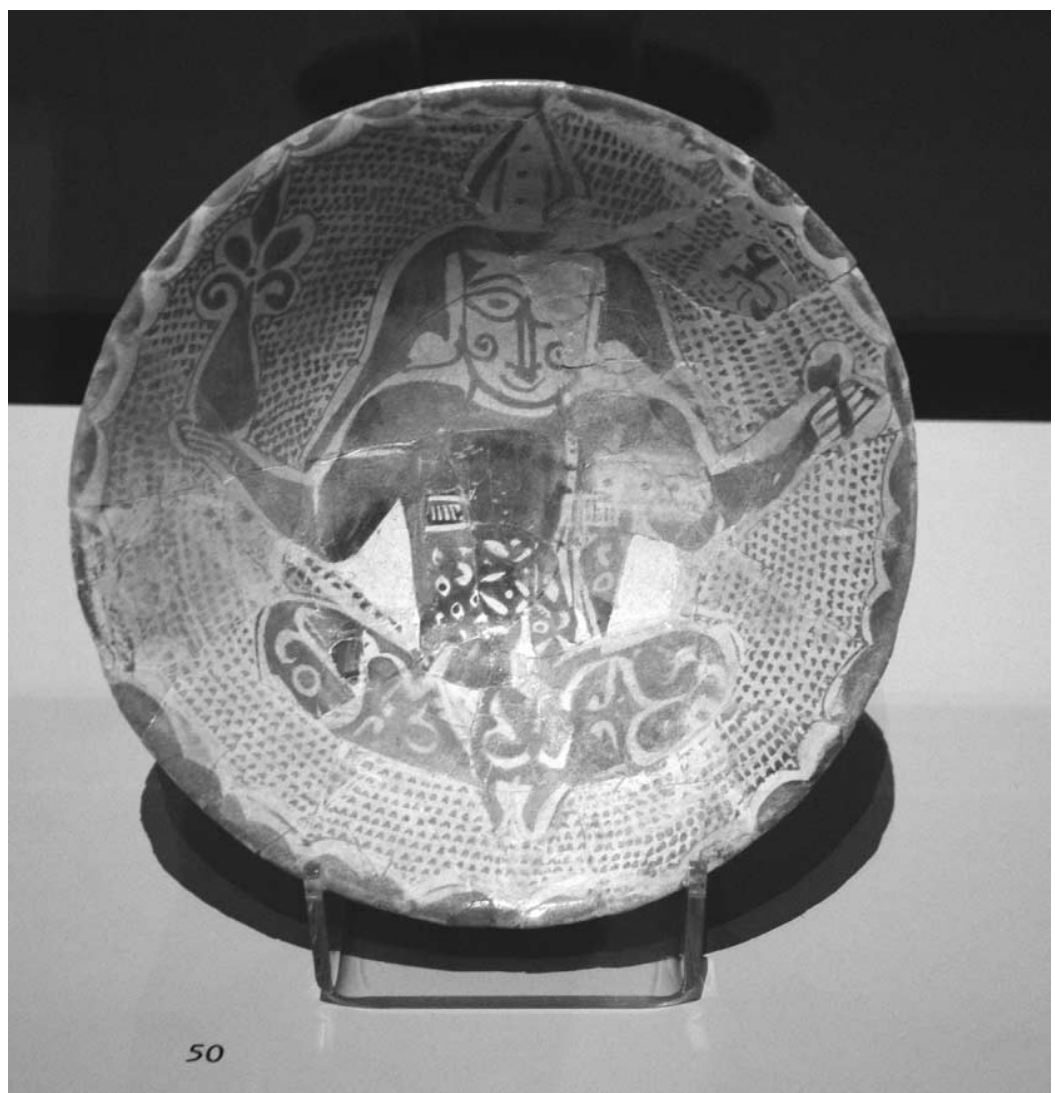

Figure 12.

Lusterware bowl from Mesopotamia, ca. 800-900 CE, with seated figure in a topknot whose iconography is likely derived from Buddhist models in Bactria.

Ashmolean Museum EA 1956.66. Display photograph: Jaś Elsner. Color version available as an online enhancement.

(fig. I3). Earlier in the same gallery, we put a reliquary from Gandhara (an area spanning modern Pakistan and Afghanistan) that contained two coins and a small thimble-like silver box inside which were some tiny fragments of gold, some dark pearls, and a few very little pieces of bone (fig. 6, left-hand side). Before both of these, as you enter the room, is a wonderful ninth- or tenth-century Chinese painting in ink on paper, found in the caves of Dunhuang and now in the British Library, that used the 259 characters of the text of a famous (and famously 
Figure 13

Stupa with figures of the Buddha, from Bodhgaya in India, ca. 800900 CE. Ashmolean Museum EAOS. 58. Display photograph: Jaś Elsner. Color version available as an online enhancement.

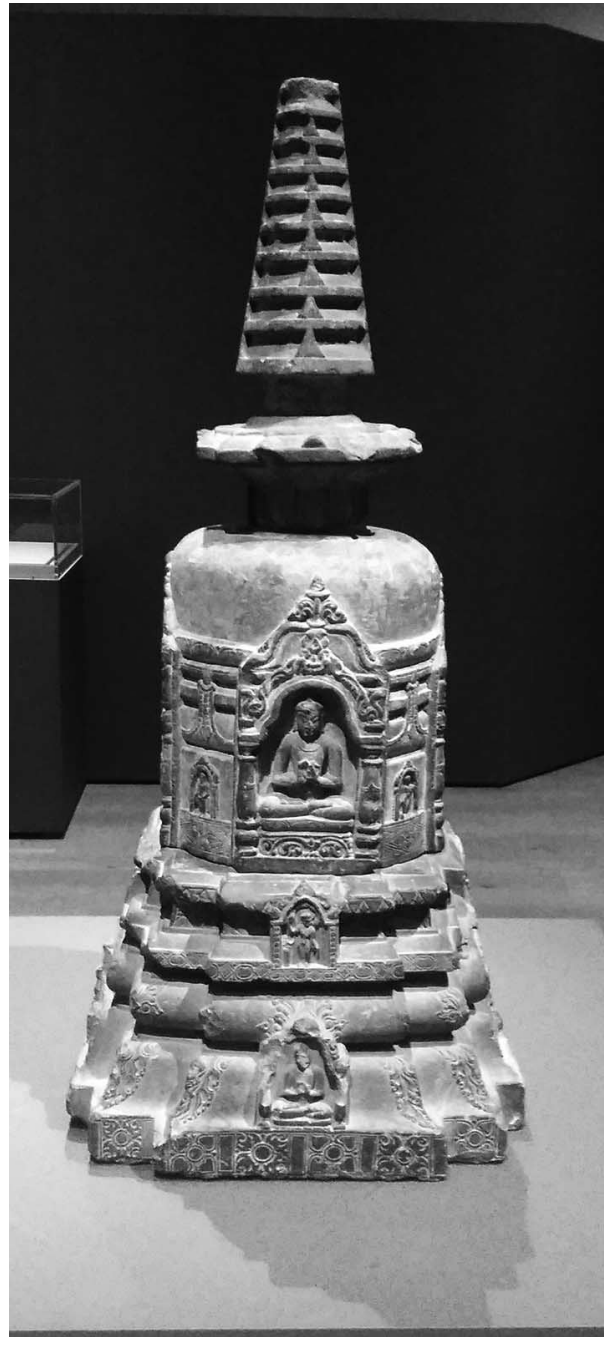


brief) Mahayana scripture, the Heart Sutra, to make the shape of a pagoda, the Chinese form of a stupa (fig. I4). Since stupas were reliquary mounds, beneath which relics were buried and which Buddhist devotees would circumambulate (circling clockwise to the right), our reliquary (and its relics) spoke to the stupa-being the kind of object that would have justified the making of the monument by being interred underneath. The Heart Sutra, itself a sacred text and one that received veneration in its ancient Indian and Chinese contexts by being written in the shape of an object to which devotion was normally given, itself becomes a relic, the kind of thing that was embedded beneath a stupa. These objects taken together make an argument for, or perhaps one should say an evocation of, the sanctity of space, the guarantee of that sacredness through the relic beneath, the possibility that textual commentary in visual form can itself acquire the qualities of holy and reliquary power. They imply the lived and ritual nature of religion, as it uses space, text, and objects (some visible and some hidden through burial) to construct a site where the subjectivity of response is in part shaped through devotion.

We did not plan these connections literally or deliberately, but when the objects were juxtaposed in this way, the argument made itself. We may have chosen the sutra because we wanted something Chinese from the Silk Road, the reliquary because we wanted something from Gandhara within the orbit of the Kushan empire and related to the mix of Greek- and Persian-influenced cultures west of the Hindu Kush, the stupa because we wanted the largest characteristic monument of that kind we could easily get (this one did not need borrowing since it is in the Ashmolean's own collection). But once they are placed together, they make their own story-not part of the exhibition's consciously intended narrative nor part of its plan, but a form of knowledge available to be taken away by visitors and curators. There are kinds of knowledge that, though they are produced in the process of exhibition making and indeed are the 
Figure 14

Chinese text of the Heart Sutra, presented as a pagoda, ink on paper, from Dunhuang, China, ca. 800-900 CE. British Library OR 8210/S. 4289 recto. Display photograph: Jaś Elsner. Color version available as an online enhancement.

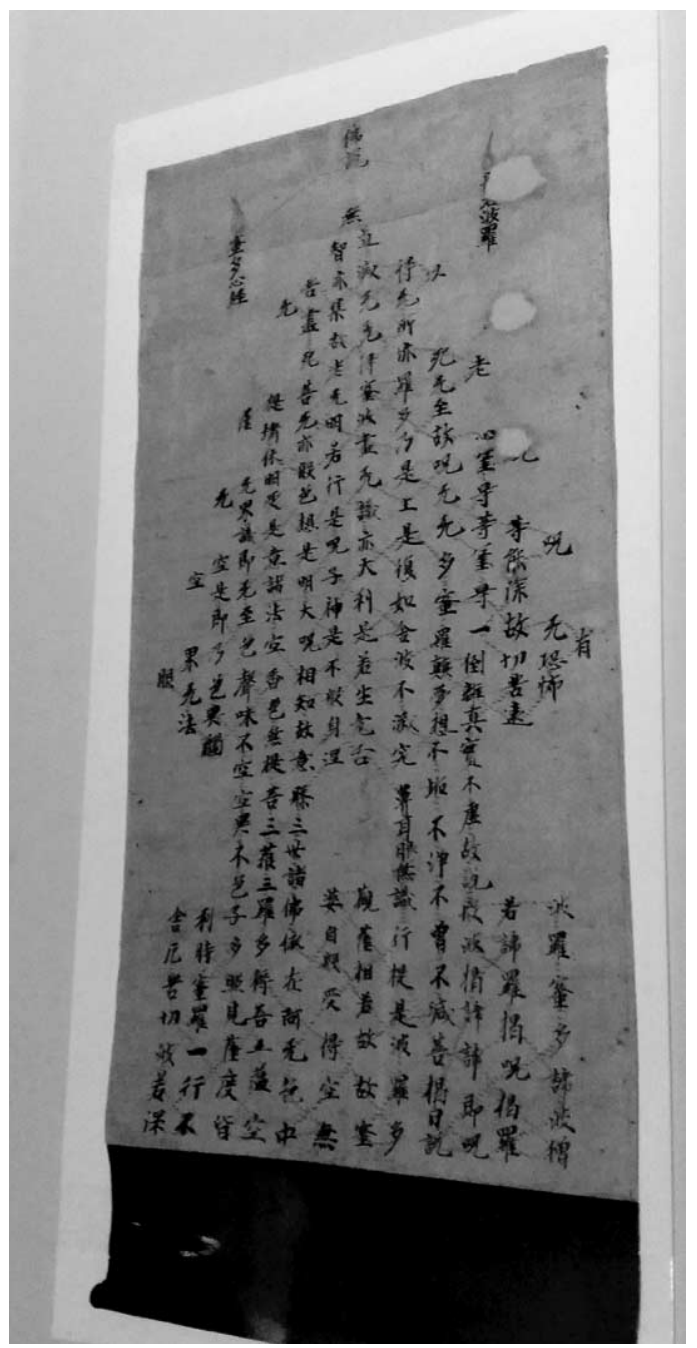


result of that process, are not themselves part of the show's core narrative, since the narrative needs to be decided upon at a very early stage for practical reasons. Arguably this is one of the most exciting aspects of exhibition making, and one of the reasons that the gulf that currently exists between museum professionals and academics-a much larger gulf than a hundred or even fifty years ago-is not in fact to the benefit of either profession, or of the museum visitor.

Exhibition knowledge, one might say, is generated at the point of the visitor's reception, but in relation to the package of objects gathered and the choreography of their particular display. If you go to an exhibition many times-as I have had to do in this case, in taking round many varieties of visitors from donors to the show, donors to the museum, official grandees, family friends, colleagues, groups of students, or fellow scholars-then the stories one may tell, depending on which objects one chooses to focus on, may change, deepen, refract. In the end, I think an exhibition is a form of knowledge much closer to a literary text or work of art than it is to an academic argument or an essay. It is something capable of being explored in many ways, too rich for a single proposition. For someone who has spent his life as an art historian because he could never rise to being an artist, there is something heartwarming about being able to approach the making of art through organizing an exhibition. 


\section{Notes}

I thank my cocuratorial team in the Imagining the Divine show: Philippa Adrych, Nadia Ali, Robert Bracey, Katherine Cross, Dominic Dalglish, Stefanie Lenk, Maria Lidova, Georgi Parpulov, Yuthika Sharma, and Rachel Wood. I am particularly grateful to Dom and Stefi for their comments on an earlier draft.

I. Jaś Elsner, Stefanie Lenk, et al., Imagining the Divine: Art and the Rise of World Religions (Oxford: Ashmolean Museum, 2017).

2. Stefanie Lenk, "Iconoclasm," in Elsner et al., Imagining the Divine, I28-33; Nadia Ali and Rachel Wood, "The Emergence of Islamic Art," in Elsner et al., Imagining the Divine, I35-59, esp. I57-59; Nadia Ali, "A Lustreware Bowl," in Elsner et al., Imagining the Divine, I60-6I. 